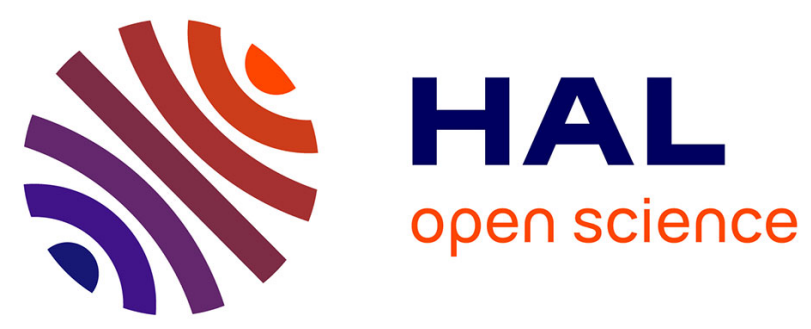

\title{
Comparison of 68Ga-Dotatate PET/CT and 18F-FDOPA PET/CT for the diagnosis of pancreatic neuroendocrine tumors in a MEN1 patient
}

Marine Jullien, Thibault Reichert, Pascal D'anella, Frederic Castinetti, Anne A. Barlier, Thierry Brue, David Taieb, Thomas Cuny

\section{To cite this version:}

Marine Jullien, Thibault Reichert, Pascal D'anella, Frederic Castinetti, Anne A. Barlier, et al.. Comparison of 68Ga-Dotatate PET/CT and 18F-FDOPA PET/CT for the diagnosis of pancreatic neuroendocrine tumors in a MEN1 patient. Annales d'Endocrinologie, 2020, 81 (1), pp.39-43. 10.1016/j.ando.2019.11.001 . hal-03121982

\section{HAL Id: hal-03121982 \\ https://hal.science/hal-03121982}

Submitted on 24 Feb 2021

HAL is a multi-disciplinary open access archive for the deposit and dissemination of scientific research documents, whether they are published or not. The documents may come from teaching and research institutions in France or abroad, or from public or private research centers.
L'archive ouverte pluridisciplinaire HAL, est destinée au dépôt et à la diffusion de documents scientifiques de niveau recherche, publiés ou non, émanant des établissements d'enseignement et de recherche français ou étrangers, des laboratoires publics ou privés. 


\title{
Comparison of 68Ga-Dotatate PET/CT and 18F-FDOPA PET/CT for the diagnosis of pancreatic neuroendocrine tumors in a MEN1 patient
}

\author{
Comparaison du (68)Ga-DOTATATE TEP/TDM et du (18)F-FDOPA TEP/TDM pour le \\ diagnostic des tumeurs neuroendocrines pancréatiques chez une patiente atteinte \\ de NEM1
}

\author{
Marine Jullien ${ }^{\mathrm{a}}$, Thibault Reichert ${ }^{\mathrm{b}}$, Pascal D’Anella ${ }^{\mathrm{c}}$, Frédéric Castinetti ${ }^{\mathrm{a}}$, Anne Barlier ${ }^{\mathrm{d}}$, \\ Thierry Brue ${ }^{a}$, David Taieb ${ }^{b}$, Thomas Cuny ${ }^{a, *}$

\footnotetext{
a Inserm U1251, service d'endocrinologie, Marseille Medical Genetics, Hôpital de la Conception, Aix-Marseille Université, AP-HM, Marseille, France

b Service de médecine nucléaire, hôpital de la Timone, Aix-Marseille Université, AP-HM, Marseille, France

' Service d'endocrinologie, centre hospitalier d'Avignon, Avignon, France

d Inserm U1251, laboratoire de biologie moléculaire, Marseille Medical Genetics, Hôpital de la Conception, Aix-Marseille Université, AP-HM, Marseille,

France
}

\section{A B S T R A C T}

Context. - Pancreatic neuroendocrine tumors (PNETs) occur in more than $80 \%$ of patients with multiple endocrine neoplasia type 1 (MEN1) syndrome, with predominance of small $(<1 \mathrm{~cm})$ non-functioning tumors, followed by gastrinomas and insulinomas. Due to their small size, the diagnostic performance of conventional MRI and CT imaging is highly variable, with a real risk of false-negatives. Functional imaging on 111In-DTPA-Octreotide SPECT somatostatin receptor scintigraphy (Octreoscan ${ }^{\circledR}$ ) is the modality of choice, but shows only $80 \%$ sensitivity. Alternatively, 18F-fluorodihydroxyphenylalanine (FDOPA) and, more recently, $68 \mathrm{Ga}$-Dotatate PET/CT imaging are valuable options in case of negative Octreoscan ${ }^{\circledR}$.

Case report. - A 55 old-year woman diagnosed with MEN1 syndrome, presented with multiple asymptomatic but progressive PNETs revealed on ultrasound endoscopy. Octreoscan ${ }^{\circledR}$ was negative, as was 18F-FDOPA PET/CT, whereas 68Ga-Dotatate PET/CT detected all PNETs found on endoscopy.

Conclusion. - We here report the first case of a MEN1 patient who successfully underwent a 68GaDotatate PET/CT for detection and follow-up of PNETs, while both Octreoscan ${ }^{\circledR}$ and 18F-FDOPA PET/CT were negative.

\section{R É S U M É}

Contexte. - Les tumeurs neuroendocrines pancréatiques (TNEPs) surviennent chez $80 \%$ des patients atteints de néoplasie endocrinienne multiple de type 1 (NEM1), avec une prédominance de petites tumeurs $(<1 \mathrm{~cm})$, non fonctionnelles, suivies par les gastrinomes et les insulinomes. Du fait de leur petite taille, la performance diagnostique de l'imagerie conventionnelle (IRM et TDM) est variable, pouvant conduire à d'authentiques situations de faux-négatifs. Le 111In-DTPA-Octreotide SPECT (Octréoscan ${ }^{\circledR}$ ) (scintigraphie des récepteurs de la somatostatine) constitue l'imagerie fonctionnelle de préférence, mais avec une sensibilité de seulement $80 \%$. En parallèle, le développement de l'imagerie par tomographie par émission de positons couplée au scanner (TEP/TDM) utilisant la 18Ffluorodihydroxyphenylalanine ((18)F-FDOPA) ou plus récemment le 68(Ga)-DOTATATE sont des options intéressantes, en cas d'Octréoscan ${ }^{\circledR}$ négatif.

Cas clinique. - Une patiente âgée de 55 ans, suivie pour une NEM1, fut admise en raison de TNEPs multiples non symptomatiques et progressives objectivées en écho-endoscopie. L’Octréoscan ${ }^{\circledR}$ était non contributif, de même que la (18)F-FDOPA TEP/TDM, alors que le 68(Ga)-DOTATATE TEP/TDM identifiait l'ensemble des TNEPs détectées en endoscopie. 


\section{Introduction}

Multiple endocrine neoplasia type 1 (MEN1) is an autosomal dominant disorder characterized by the occurrence of parathyroid, anterior pituitary and pancreatic neuroendocrine neoplasms (PNENs) [1]. It is genetically related to mutations in the MEN1 gene, causing an automosal dominant inheritance with more than 1500 mutations currently described. Molecular alterations affecting the MEN1 signaling pathway have been identified in familial as well as in sporadic PNENs [2]. Furthermore, the latter occur in more than $80 \%$ of MEN1 patients, with an overrepresentation of small (i.e. $<1 \mathrm{~cm}$ in size) and multiple non-functioning tumours followed by gastrinomas and insulinomas [3]. The diagnosis of PNENs relies on both conventional imaging such as CT scan or pancreatic MRI and nuclear medicine imaging modalities, headed by In-pentetreotide single-photon emission computed tomography (CT) (octreoscan). However, in the particular setting of MEN1, octreoscan fails to image 35 to $50 \%$ of PNENs $<1 \mathrm{~cm}$ in diameter [4]. As such the work conducted by Morgat et al. is of importance as it showed in a series of 19 patients with MEN1, respective sensitivities of $20 \%$ for octreoscan and 76\% for (68)Ga-DOTA-TOC PET/CT for the detection of duodenopancreatic NENs [5]. (68)Ga-DOTA tracers used the PET technique and have high affinity for the somatostatin receptor subtype 2 (SSTR2), which is highly expressed in neuroendocrine neoplasms [6]. Besides SSTR2-derived imaging modalities, F-FDOPA PET/CT also emerged as reliable imaging technique for the detection of NENs, especially in cases of pancreatic insulinomas (after carbidopa premedication) [7] or small intestine neuroendocrine neoplasms (SiNENs) [8]. Its performance for the diagnosis of (other) PNENs in the setting of MEN1 syndrome is currently unknown.

We here report the first case of a MEN1 patient who successfully underwent a 68(Ga)-DOTATATE PET/CT for the detection of small multiple PNENs after both negative 18F-FDOPA PET/CT (with carbidopa premedication) and 111 In-DTPA-Octreotide SPECT (OctreoScan).

\section{Case report}

In 2018, a 55 year-old woman was referred to our department for the follow up of a MEN1 syndrome diagnosed in 1999. Her diagnosis was made in a context of genetic screening because her sister was the index case and exceptionally, she belonged to a family of 11 siblings (Fig. 1) and carried the MEN1 mutation Exon 9, c.1192delc; p.(Gln398Argfs*47). In her past history, she has been treated for a primary hyperparathyroïdism (subtotal parathyroidectomy) secondary to multiglandular disease at the age of 45 and is also regularly followed up for a non-secreting $3 \mathrm{~mm}$-right sided pituitary microadenoma. She underwent several abdominal CT-scan which found two hypervascular lesions of $8 \mathrm{~mm}$ each, at the posterior face of both the pancreatic body and the tail, respectively. An echoendoscopy was subsequently performed and further identified two more lesions in the pancreas between the body and the tail: in total, there were 4 lesions whose maximal diameter size were $10,12,14$ and $15 \mathrm{~mm}$, respectively. An ultrasound-guided fine needle aspiration was performed on the larger lesion and the histology was consistent with a PNEN grade 1 (Ki67 < $2 \%$, no mitose). A complete hormonal assessment was strictly negative which meant that those PNEN lesions were non-secreting. Importantly, there was no argument for the possibility of an (occult) insulinoma. As compared to the previous echoendoscopy, the size of the $15-\mathrm{mm}$ lesion increased, the reason why we sought for another and less invasive imaging modality in the follow-up of this patient. We thus performed an octreoscan (132MBq Octreotide indium 111) which was negative for all the lesions previously described (Fig. 2). We, thus, referred the patient to the nuclear medicine for the realization of a (18)F-FDOPA PET/CT with carbidopa premedication (Timone, GE Discovery 710 Premedication with Carbi dopa (200 mg). Activité: $179 \mathrm{MBq}-4.53 \mathrm{mCi}$,). However, the lesions did not uptake at all the radiotracer and the exam was considered as non contributive (Fig. 2). Eventually, a multidisciplinary decision suggested to perform 68(Ga)-DOTATATE PET/CT (hôpital de la Timone, PET CT Discovery 710; PDL 236mGy.cm, CTDI 2,3mGy). All of the 4 lesions showed an uptake of the radiotracer with respective maximum SUV of 28.4 (lesion 1), 7.2 (lesion 2), 7.4 (lesion 3) and 14.6 (lesion 4), respectively (Fig. 3B). There was no hypermetabolic adenopathy or further lesions. The patient is currently treated by somatostatin analogs monthly.

\section{Discussion}

The diagnosis of digestive neuroendocrine neoplasms in the context of MEN1 remains a real challenge in clinical practice, in more than one way. First, PNENs represent one of the main cause of death in patients with MEN1, a majority of these being attributable to gastrinomas, responsible for gastric acid hypersecretion, multiple duodenal ulcers and eventually life-threatening gastrointestinal haemorrhage [9]. Second, MEN1related PNENs are, unlike their sporadic counterparts, usually small (i.e., $<1 \mathrm{~cm}$ ), multiple, and occur on a background of diffuse pancreatic microadenomatosis [3]. Based on those characteristics, classic imaging procedures such as C T scan, MRI or Octreoscan ${ }^{\circledR}$ can be faulted in terms of sensitivity as well as in terms of specificity, the latter being related to the fact that different phenotypes

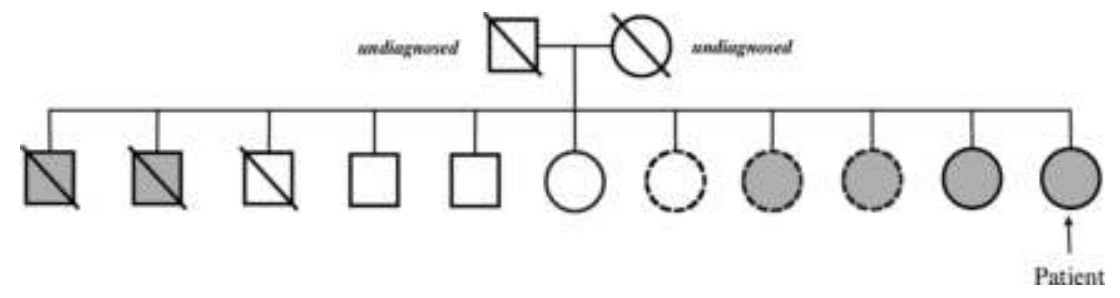

Fig. 1. Family tree of the proband and her siblings. 

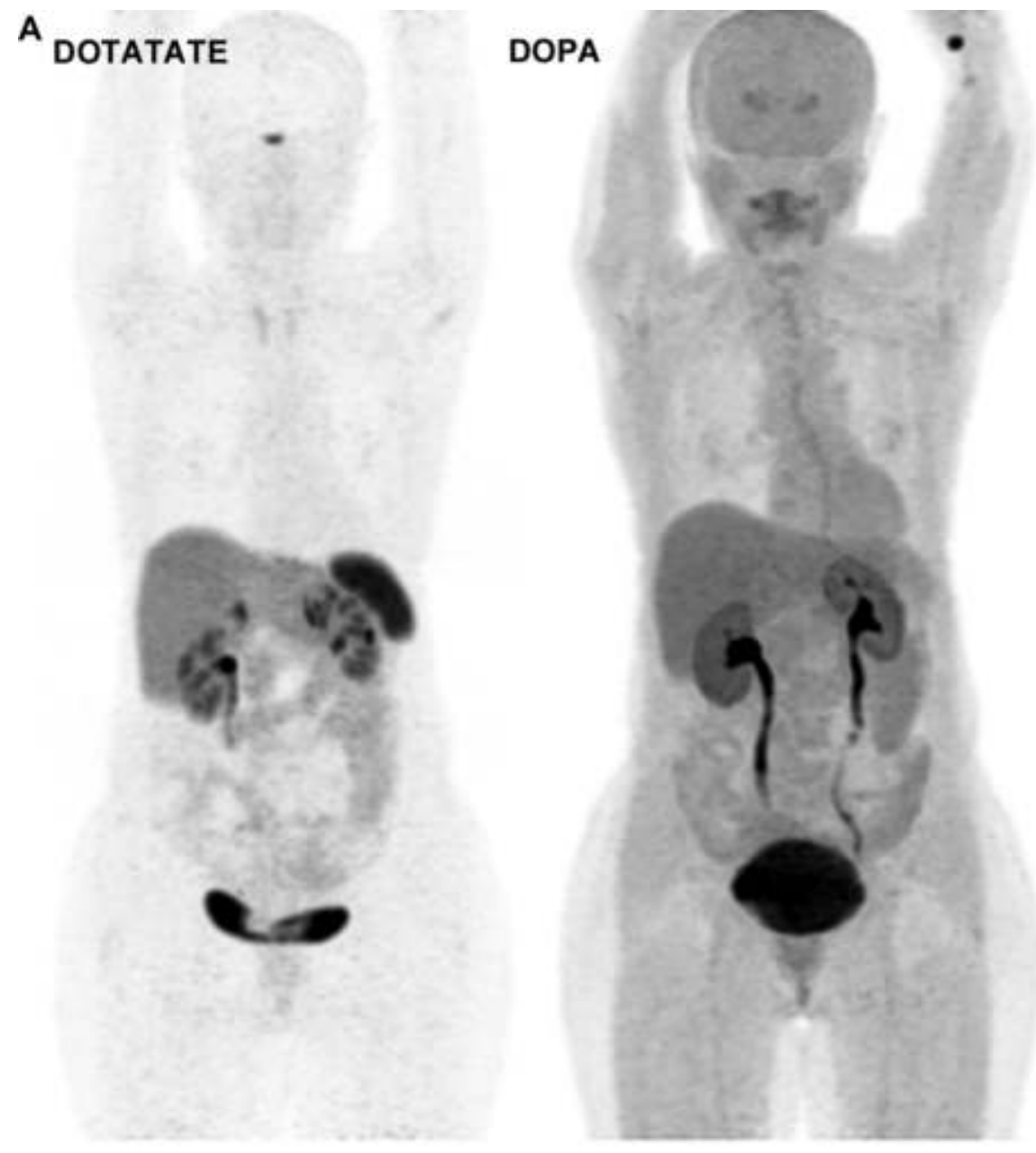

B
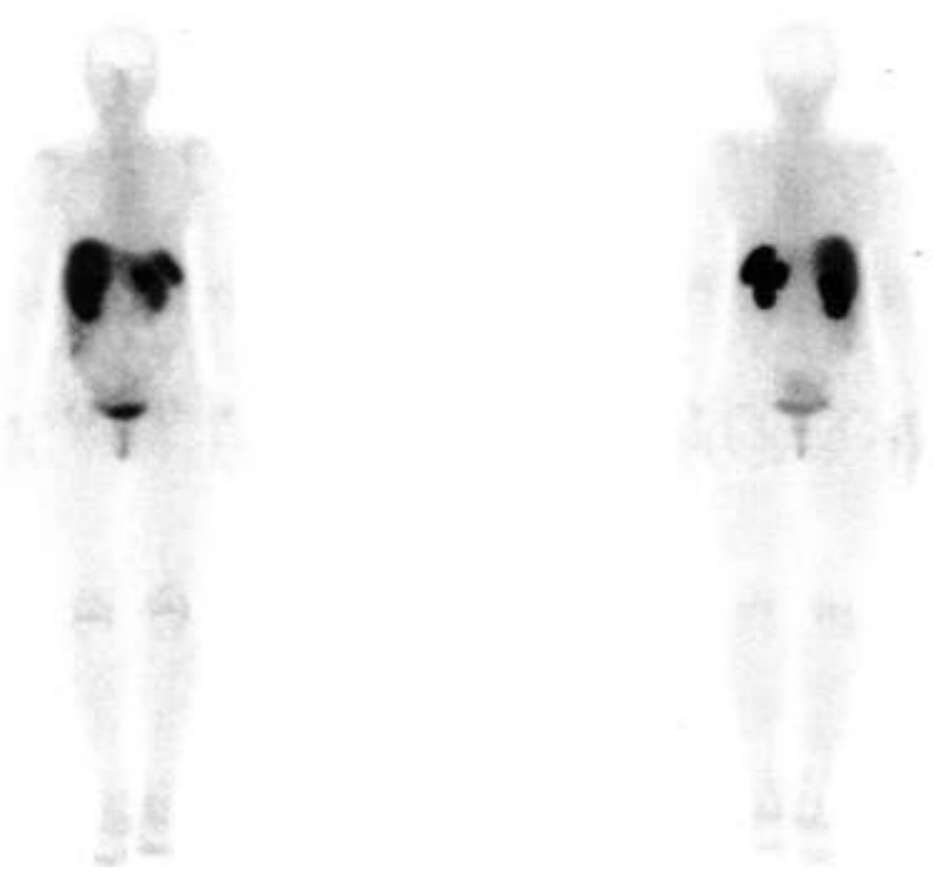

Fig. 2. A. MIP (Maximal Intensity Projections) pictures of (18)F-FDOPA and (68)Ga-DOTATATE of the patient. B. Octreoscan ${ }^{\circledR}$ of the patient which was non contributive for the detection of the pancreatic neuroendocrine lesions. 

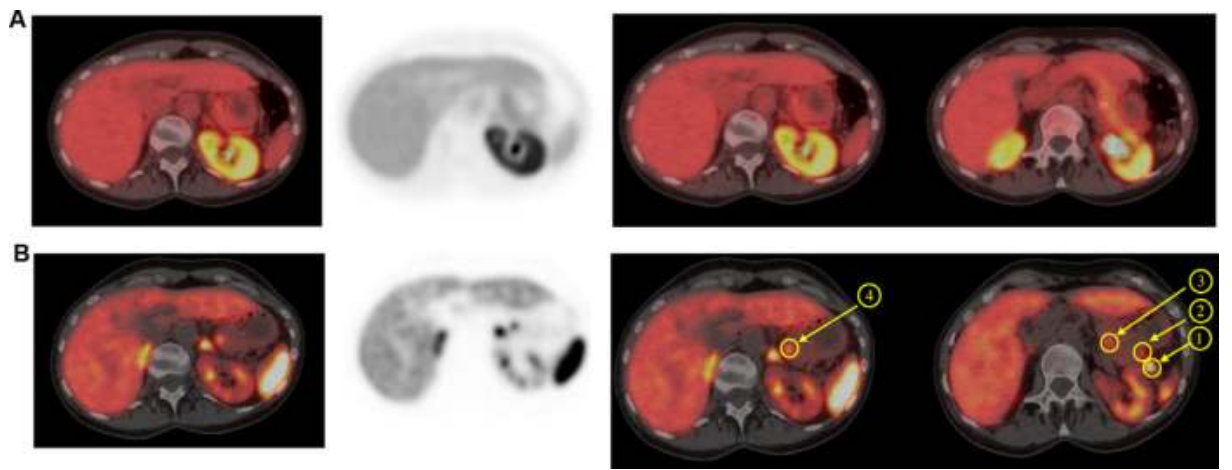

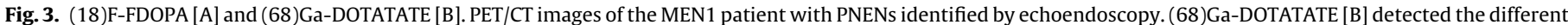
lesions (arrows 1 to 4 ) in the pancreas while (18)F-FDOPA was negative.

Table 1

Affinity profiles (IC50) for human somatostatin receptors (SSTR) of a series of somatostatin analogs.

\begin{tabular}{|c|c|c|c|c|c|}
\hline Peptides & SSTR1 & SSTR2 & SSTR3 & SSTR4 & SSTR5 \\
\hline Somatostatin 28 & $5.2 \pm 0.3$ & $2.7 \pm 0.3$ & $7.7 \pm 0.9$ & $5.6 \pm 0.4$ & $4.0 \pm 0.3$ \\
\hline Octreotide & $>1,000$ & $2.0 \pm 0.7$ & $187 \pm 55$ & $>1,000$ & $22.6 \pm 6$ \\
\hline Lanreotide & $>1,000$ & $1.8 \pm 3.4$ & $771 \pm 229$ & $>1,000$ & $53 \pm 12$ \\
\hline In-DTPA-octreotide (pentetreotide) & $>1,000$ & $22 \pm 3.6$ & $182 \pm 13$ & $>1,000$ & $237 \pm 52$ \\
\hline Ga-DOTATOC & $>1,000$ & $2.5 \pm 0.5$ & $613 \pm 140$ & $>1,000$ & $73 \pm 21$ \\
\hline Ga-DOTATATE & $>1,000$ & $0.2 \pm 0.04$ & $>1,000$ & $300 \pm 140$ & $377 \pm 18$ \\
\hline
\end{tabular}

All values are IC50 \pm SEM in nM. Adapted from [18].

of PNENs can coexist in a MEN1 patient (insulinoma and nonsecreting tumors for instance). In the case of insulinoma, it is well established that the density of SSTR2 is lower as compared to other types of PNENs, which could, coupled to the small size of the lesion, be a source of false-negative during Octreoscan ${ }^{\circledR}$. Today, echoendoscopic ultrasound remains the "gold-standard" to both accurately localize lesions equivocal of PNENs and perform histopathological analysis, as illustrated in our clinical case [1]. However, its invasive procedure as well as its exclusive focus of the pancreas gland, considerably limit its use for appreciating the extension of the disease (e.g. liver metastasis) and for the periodic followup of the patient. Due to its low sensitivity, octreoscan has been recently challenged by other nuclear imaging modalities, such as SSTR2-PET/CT using Gallium-68 (Table 1). There are currently three studies which assessed the diagnosis value of (68)Ga-DOTATATE or -DOTATOC PET/CT for the diagnosis of PNENs in MEN1 patients [10-12]. In the study by Morgat et al. ( $N=19)$, patients with MEN1) the sensitivity of (68)Ga-DOTATOC PET/CT was $76 \%$ as compared to $20 \%$ with octreoscan, respectively $(P<0.0001)$. Moreover, $(68) \mathrm{Ga}-$ DOTATOC PET/CT detected lesions of smaller size than octreoscan $(10.7 \pm 7.6$ and $15.2 \pm 5.9 \mathrm{~mm}$, respectively, $P<0.03)$ [10]. Likewise, the results observed by Lastoria et al. ( $N=18$ MEN1patients) and Sadowski et al. ( $N=26$ MEN1 patients), also confirmed a higher sensitivity of (68)Ga-DOTATATE PET/CT as compared to conventional imaging (including octreoscan) for the detection of both PNEN lesions in a MEN1 patients as well as the diagnosis of liver metastasis [11,12]. Besides SSTR2-related imaging, (18)F-FDOPA PET/CT is now routinely used in many referal centers to confirm the neuroendocrine nature of pancreatic lesions. A carbidopa premedication is commonly proposed to optimize the sensitivity of this imaging procedure in the detection of insulinomas [7], as well as in case of non-secreting PNENs [13]. In the latter study, its sensivity was even better when compared to Octreoscan ${ }^{\circledR}$. A preliminary study suggested a better diagnosis performance of (68)Ga-DOTANOC over (18)F-FDOPA for the detection of digestive NENs [14], however, the respective performance of these imaging modalities in the setting of MEN1 remains unstudied. Overall, it has to be recalled that significant technical differences exist between all those imaging modalities. Even though the same somatostatin receptor subtype (i.e. SSTR2) is targeted by (68)Ga-DOTATATE and In-pentetreotide, the spatial resolution of SPECT/CT is clearly lower that the one obtained with TEP/CT. Therefore, small lesions PNEN are likely less detected by Octreoscan ${ }^{\circledR}$, independently of the density of membranous SSTR2. Concerning (18)F-FDOPA PET/CT, a diffuse uptake from the pancreas usually occurs and constitutes an obvious limitation for the detection of small neuroendocrine lesions of the pancreas. In that respect, carbidopa premedication is necessary to improve the sensitivity of the exam for the analysis of the pancreas.

Our clinical case illustrates that (18)F-FDOPA PET/CT can lead to false negative results in a MEN1 patient and therefore should prompt clinicians to prefer (68)Ga-DOTATATE PET/CT. As others [15], we think based on this observation, that (68)GaDOTATATE PET/CT should be now systematically performed at the initial diagnosis and in the follow-up of a patient with a MEN1 syndrome. Another interesting aspect of this statement is that (68)Ga-DOTATATE PET/CT, when positive, could pave the way for a theranostic approach in MEN1 patients with PRRT (peptide radionuclide receptor therapy) $\mathrm{using}^{177}$ Lu-DOTATATE [16]. The latter recently showed to be a valuable therapeutic option in patients with SiNENs [17], although its efficacy in PNENs, especially in MEN1, remains to be studied.

\section{Ethical approval}

This article does not contain any studies with animals and human participants performed by any of the authors.

\section{Informed consent}

Informed consent was obtained from all individual participants included in the study.

\section{Funding}

This study was not funded. 


\section{Disclosure of interest}

The authors declare that they have no competing interest.

\section{References}

[1] Thakker RV, Newey PJ, Walls GV, Bilezikian J, Dralle H, Ebeling PR, et al. Clinical practice guidelines for multiple endocrine neoplasia type 1 (MEN1). J Clin Endocrinol Metab 2012;97:2990-3011, http://dx.doi.org/10.1210/jc.2012-1230.

[2] Scarpa A. The landscape of molecular alterations in pancreatic and small intestinal neuroendocrine tumours. Ann Endocrinol (Paris) 2019;80:153-8, http://dx.doi.org/10.1016/j.ando.2019.04.010.

[3] Yates CJ, Newey PJ, Thakker RV. Challenges and controversies in management of pancreatic neuroendocrine tumours in patients with MEN1. Lancet Diabetes Endocrinol 2015;3:895-905, http://dx.doi.org/10.1016/ S2213-8587(15)00043-1.

[4] Ito T, Jensen RT. Imaging in multiple endocrine neoplasia type 1: recent studies show enhanced sensitivities but increased controversies. Int J Endocr Oncol 2016;3:53-66, http://dx.doi.org/10.2217/ije.15.29.

[5] Vélayoudom-Céphise FL, Morgat C, Schwartz $P$, Nunes ML, Guyot $M$, Schulz J, et al. Étude comparative de la TEP au68GaDOTATOC et de la tomoscintigraphie à l'111In-DTPA-octréotide pour le dépistagedes tumeurs neuroendocrinesduodénopancréatiques des patients porteursd'une NEM1: étude pilote. Ann Endocrinol (Paris) 2015;76:322-3, http://dx.doi.org/10.1016/j.ando.2015.07.927.

[6] O’Toole D, Saveanu A, Couvelard A, Gunz G, Enjalbert A, Jaquet P, et al. The analysis of quantitative expression of somatostatin and dopamine receptors in gastro-entero-pancreatic tumours opens new therapeutic strategies. Eur J Endocrinol 2006;155:849-57, http://dx.doi.org/10.1530/eje.1.02307.

[7] Leroy-Freschini B, Amodru V, Addeo P, Sebag F, Vix M, Brunaud L, et al. Early 18F-FDOPA PET/CT imaging after carbidopa premedication as a valuable diagnostic option in patients with insulinoma. Eur J Nucl Med Mol Imaging 2019;46:686-95, http://dx.doi.org/10.1007/s00259-018-4245-3.

[8] Santhanam P, Taïeb D. Role of ${ }^{18}$ F-FDOPA PET/CT imaging in endocrinology. Clin Endocrinol (Oxf) 2014;81:789-98, http://dx.doi.org/10.1111/cen.12566.
[9] Goudet P, Murat A, Binquet C, Cardot-Bauters C, Costa A, Ruszniewski P, et al Risk factors and causes of death in MEN1 Disease. A GTE (Groupe d'Étude des Tumeurs Endocrines) cohort study among 758 patients. World J Surg 2010;34:249-55, http://dx.doi.org/10.1007/s00268-009-0290-1.

[10] Morgat C, Vélayoudom-Céphise F-L, Schwartz P, Guyot M, Gaye D, Vimont D, et al. Evaluation of 68Ga-DOTA-TOC PET/CT for the detection of duodenopancreatic neuroendocrine tumors in patients with MEN1. Eur J Nucl Med Mol Imaging 2016;43:1258-66, http://dx.doi.org/10.1007/s00259-016-3319-3.

[11] Sadowski SM, Millo C, Cottle-Delisle C, Merkel R, Yang LA, Herscovitch P, et al. Results of 68Gallium-DOTATATE PET/CT Scanning in Patients with Multiple Endocrine Neoplasia Type 1. J Am Coll Surg 2015;221:509-17, http://dx.doi.org/10.1016/j.jamcollsurg.2015.04.005.

[12] Lastoria S, Marciello F, Faggiano A, Aloj L, Caracò C, Aurilio M, et al. Role of 68Ga-DOTATATE PET/CT in patients with multiple endocrine neoplasia type 1 (MEN1). Endocrine 2016;52:488-94, http://dx.doi.org/10.1007/s12020-015-0702-y.

[13] Helali M, Addeo P, Heimburger C, Detour J, Goichot B, Bachellier P, et al. Carbidopa-assisted 18F-fluorodihydroxyphenylalanine PET/CT for the localization and staging of non-functioning neuroendocrine pancreatic tumors. Ann Nucl Med 2016;30:659-68, http://dx.doi.org/10.1007/s12149-016-1110-y.

[14] Ambrosini V, Tomassetti P, Castellucci P, Campana D, Montini G, Rubello D, et al. Comparison between 68Ga-DOTA-NOC and 18F-DOPA PET for the detection of gastro-entero-pancreatic and lung neuro-endocrine tumours. Eur J Nucl Med Mol Imaging 2008;35:1431-8, http://dx.doi.org/10.1007/s00259-008-0769-2.

[15] Marx SJ. Recent Topics Around Multiple Endocrine Neoplasia Type 1. J Clin Endocrinol Metab 2018;103:1296-301, http://dx.doi.org/ 10.1210/jc.2017-02340.

[16] Vija L, Dierickx L, Courbon F. Receptor radionuclide targeting for neuroendocrine tumors (NET) diagnostic and therapy. Ann Endocrinol (Paris) 2019;80:166-71, http://dx.doi.org/10.1016/j.ando.2019.04.005.

[17] Strosberg JK. renning $E^{177}$ Lu-Dotatate for Midgut Neuroendocrine Tumors. N Engl J Med 2017;376:1390-2, http://dx.doi.org/10.1056/NEJMc1701616.

[18] Cuny T, Saveanu A, Taïeb D, Barlier A. Targeting somatostatin receptors in gastroenteropancreatic neuroendocrine tumours (GEPNETs): which radiotracers for which tumours? Med Nucl 2010;34:310-7, http://dx.doi.org/10.1016/j.mednuc.2010.02.003. 